\title{
América Latina y El Caribe: Ayuda Oficial al Desarrollo EN EL PUNTO DE INFLEXIÓN DEL MILENIO ${ }^{I}$
}

\author{
Sergio Tezanos Vázquez* y Aitor Martínez de la Cueva Astigarraga**
}

Fecha de recepción: 1 de junio de 2010. Fecha de aceptación: 11 de agosto de 2010.

\section{RESUMEN}

Los países de América Latina y El Caribe (ALC) han sido importantes receptores de AOD desde la creación del Comité de Ayuda al Desarrollo de la OCDE. No obstante, su participación en el sistema de ayuda se ha visto alterada en los primeros años del siglo XXI como consecuencia de los cambios introducidos en la agenda internacional de desarrollo. La estrategia de los ODM concede especial atención a los países que retrasan la consecución universal de los objetivos, lo que motiva la reasignación de la ayuda desde los países de desarrollo intermedio hacia los países más pobres. En este contexto, dado el positivo avance de ALC en los ODM, el nuevo mapamundi de la ayuda aminora la importancia de la región. Este artículo analiza los flujos de AOD desembolsados a ALC desde 1990 y ofrece propuestas de reforma para construir un sistema de ayuda más eficiente, que compense la pérdida de volumen con incrementos en calidad.

\section{PALABRAS CLAVE}

América Latina y El Caribe (ALC), ayuda oficial al desarrollo (AOD), agenda internacional de desarrollo, Objetivos de Desarrollo del Milenio (ODM), eficacia de la ayuda.

\footnotetext{
1 El presente texto forma parte del proyecto de investigación "Las perspectivas de América Latina ante la nueva agenda global de desarrollo y la coordinación de las políticas geográficas de los donantes”, que desarrolla la Cátedra de Cooperación Internacional y con Iberoamérica, con el apoyo de la Agencia Española de Cooperación Internacional para el Desarrollo (AECID). Los autores agradecen los comentarios de Rafael Domínguez, Ainoa Quińones Montellano y dos evaluadores anónimos. Los autores son responsables de los juicios y posibles errores. Una versión previa de este trabajo apareció publicada en el libro América Latina y El Caribe. Mapa estratégico para la cooperación del siglo Xxi. Tezanos (dir.), (2010).

* Universidad de Cantabria, Cátedra de Cooperación Internacional y con Iberoamérica, correo electrónico: tezanoss@ unican.es

** Universidad de Cantabria, Cátedra de Cooperación Internacional y con Iberoamérica, correo electrónico: mcuevaaf @ unican.es
} 


\begin{abstract}
The countries of Latin America and the Caribbean (LAC) have been large recipients of official development aid (ODA) since the creation of the OECD's Development Aid Committee. Nevertheless, their participation in the aid system has changed in the opening years of the $21 \mathrm{st}$ century as a consequence of changes introduced in the international development agenda. The millennium development goals (MDG) strategy concedes special attention to countries that challenge the universal securing of the goals, leading to the reallocation of aid from the countries with intermediate levels of development to the poorest countries. In this context, given the positive advance of the LAC in the MDG, the new world aid map reduces the importance of the region. This article analyzes the ODA flows sent to LAC since 1990 and provides proposals for reform to build a system of aid that is more efficient, offsetting the loss of volume with increases in quality. Key terms. Latin America and the Caribbean (LAC), official development aid (ODA), international development agenda, millennium development goals (MDG), effectiveness of aid.
\end{abstract}

\title{
Résumé
}

Les pays d'Amérique latine et des Caraïbes (ALC) ont été d'importants récepteurs de l'aide officielle au développement (AOD) depuis la création du Comité d'aide au développement de l'OCDE. Néanmoins, leur participation au système d'aide s'est vu altérée au cours des premières années du XXIème siècle du fait des changements effectués dans l'agenda international de développement. La stratégie des objectifs de développement du millénaire (ODM) accorde une attention particulière aux pays qui représentent un défi pour la réalisation universelle des objectifs, ce qui motive la réassignation de l'aide des pays de développement intermédiaire vers les pays les plus pauvres. Dans ce contexte, étant donné l'avancée positive de l'ALC dans les ODM, la nouvelle mappemonde de l'aide réduit l'importance de la région. Cet article analyse les flux de AOD versées en ALC depuis 1990 et fournit des propositions de réforme pour construire un système d'aide plus efficient, qui compense la perte de volume par des élévations de la qualité.

Mots clefs : Amérique latine et les Caraïbes (ALC), aide officielle au développement (AOD), agenda international de développement, objectifs de développement du millénaire (ODM), efficacité de l'aide

\section{Resumo}

Os países de América Latina e Caribe (ALC) foram importantes receptores da ajuda oficial ao desenvolvimento (AOD) desde a criaçáo do Comitê de Ajuda ao Desenvolvimento da OCDE. Náo obstante, sua participação no sistema de ajuda se viu alterada nos primeiros anos do Século XXI como conseqüência das mudanças introduzidas na agenda internacional do desenvolvimento. A estratégia dos Objetivos do Milếnio (ODM) dá especial atenção aos países que desafiam a consecução universal dos objetivos, o que motiva a reorientação da ajuda destinada aos países de desenvolvimento intermediário para os países mais pobres. Neste contexto, dada a evoluçáo positiva de ALC nos ODM, o novo mapamundi da ajuda diminui a importância da regiáo. Este artigo analisa os fluxos de AOD desembolsados para ALC desde 1990 e oferece propostas de reforma para construir um sistema de ajuda mais eficiente, que compense a perda de volume com incrementos de qualidade.

Palavras-chave: América Latina e Caribe (ALC), ajuda oficial ao desenvolvimento (AOD), agenda internacional de desenvolvimento, Objetivos de Desenvolvimento do Milênio (ODM), eficácia da ajuda.

\section{拉丁美洲和加勒比：处于千年发展目标拐点的官方发展援助}

自经合组织（OECD）成立发展援助委员会后，拉美和加勒比国家（LAC）就是最 大的官方援助 (ODA) 接收者。但是, 在21世纪初始, 由于国际发展议程的变化导 致拉美和加勒比国家在这项援助制度中的参与发生改变。千年发展目标 (MDG) 战 略重点关注那些对该目标的实现具有普遍挑战的国家，为此将援助的再分配从中等 发展中国家转向最贫穷的国家。鉴于此背景以及拉美国家在千年发展目标中积极发 展, 新的世界援助规划对该地区的重要性减少。本文主要分析自1990年以来, 流 入拉美和加勒比国家的官方援助，并提出改革建议以建立一个更加富有效率的援助 制度, 通过提高质量来弥补数量的减少。

关键词：拉丁美洲和加勒比（LAC）官方援助(ODA) 国际发展计划

千年发展目标(MDG) 援助效果 


\section{INTRODUCCIÓN}

Desde la creación, en 1960, del Comité de Ayuda al Desarrollo, de la OCDE, los países de América Latina y El Caribe (ALC) han recibido un desembolso neto de ayuda oficial al desarrollo (AOD) de algo más de 304 mil millones de dólares, lo que equivale a un exiguo $0.48 \%$ del PIB generado conjuntamente por estas economías en ese mismo periodo. ${ }^{2}$ No obstante, la participación de ALC en el sistema de AOD ha sufrido una alteración formidable a lo largo del tiempo: si la región percibía, en promedio, 12.7\% de las ayudas mundiales en la década de los sesenta, esta cuota ha menguado drásticamente en el siglo XXI hasta posicionarse por debajo de $8 \%$.

Esta alteración no se debe tanto al progreso económico logrado por la región -puesto que los países latinoamericanos y caribeños apenas han variado, en términos comparativos, sus posiciones en el amplio espectro de rentas per cápita del mundo en desarrollo- ${ }^{3}$ como a los cambios introducidos en la agenda internacional y, más concretamente, en la definición de una estrategia de objetivos globales de desarrollo que guía las actuaciones de los donantes. En este sentido, el sistema de cooperación internacional para el desarrollo inició el siglo XXI impulsando con inusitado consenso la agenda de los Objetivos de Desarrollo del Milenio (ODM), que hace de la lucha contra la pobreza y el hambre la bandera de la acción colectiva internacional. Los ODM fueron inicialmente concebidos para ser alcanzados "a nivel global", lo que implicaba una estrategia de "cumplimiento agregado", tal y como proclamaron 189 países -desarrollados y en desarrollo- en la Declaración del milenio, firmada en Nueva York en el año 2000. Sin embargo, cinco años más tarde, durante la Cumbre del Milenio+5, se acordó modificar la cobertura geográfica de aplicación, para que trascendiera de una escala global y se aplicara país por país. Se trata de un cambio de estrategia que no resulta baladí para ALC, en tanto que entrańa un nuevo enfoque de distribución de los recursos, el cual concede especial atención a los países donde se encuentran las grandes bre-

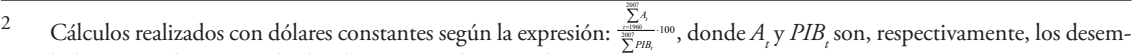
bolsos netos de AOD (todos los donantes) y el PIB en el año $t$.

3 Hoy en día los países latinoamericanos y caribeńos -con la excepción de Haití- se ubican en el estrato intermedio de la renta mundial, si bien las trayectorias de crecimiento por país han sido marcadamente heterogéneas, en correspondencia con los importantes cambios introducidos en las estrategias de crecimiento y los efectos de las políticas sociales, productivas e institucionales implementadas en cada país. No obstante, destaca el hecho de que la movilidad de los países de ALC entre los cuatro estratos de renta per cápita que define el Banco Mundial (renta baja, renta media-baja, renta media-alta y renta alta) ha sido muy limitada. Baste con comparar los listados de países por niveles de ingreso de 1978 y 2008. Los únicos movimientos detectados en la región afectan a siete países: Nicaragua y Brasil, que han experimentado movimientos de "ida y vuelta" (el primero, que descendió desde el estrato de renta media-baja al de renta baja, para recuperar recientemente su posición inicial, y, el segundo, que descendió desde el nivel de renta media-alta al de renta media-baja, retomando recientemente su posición inicial). Jamaica y Surinam, que han descendido desde el grupo de ingreso medio-alto hasta el grupo de ingreso medio-bajo. Y Barbados, Bahamas y Puerto Rico, que son los únicos que han ascendido a la escala de ingreso alto.
} 
chas carenciales que ponen en riesgo la consecución universal de los objetivos, lo que está motivando un paulatino proceso de reasignación de la ayuda desde los países con niveles de desarrollo relativamente más elevados hacia los países con menores niveles de desarrollo (Tezanos, 2010).

En este contexto, el balance conjunto de ALC en la estrategia de los ODM resulta relativamente "complaciente", en la medida en que la región avanza en casi todas las metas del milenio, exceptuando los retrocesos experimentados en los indicadores relativos a la sostenibilidad del medio ambiente y los estancamientos en términos de empleo, alfabetización de los jóvenes y planificación familiar (Tezanos y Domínguez, 2009). Por consiguiente, el nuevo trazado del mapamundi de la ayuda atempera la importancia de ALC y otorga mayor atención a los países más alejados del cumplimiento de las metas (especialmente en África subsahariana y Asia occidental), de tal manera que en el septenio posterior a la aprobación de los ODM los países de ALC recibieron una cantidad agregada de AOD ligeramente inferior a la recibida anteriormente, como consecuencia de la paulatina retirada de algunos donantes bilaterales. Esta dinámica de reasignación de los recursos se ha visto suavizada por la tendencia alcista de los desembolsos netos de AOD en el arranque del siglo XXI, que alcanzaron la histórica cifra de 120 mil millones de dólares en 2008. Esta "bonanza" ha permitido aumentar las cuotas de ayuda dirigidas a los países más pobres sin necesidad de reducir drásticamente los desembolsos dirigidos a los países de desarrollo intermedio. Así, los países de ingreso intermedio han conseguido mantener sus percepciones de ayuda per cápita, aun a pesar de haber disminuido la cantidad que recibían en la AOD global. Sin embargo, el actual escenario de crisis económica mundial amenaza con desencadenar una recesión en las cifras de AOD a partir de 2009, lo que exigirá avanzar en un proceso de reasignación que, previsiblemente, afectará con especial rigor a los países de ALC.

El presente artículo analiza cuantitativamente los flujos de AOD desembolsados a ALC desde 1990, e indaga las implicaciones que la agenda de los ODM ha comportado para la región en cuanto al porcentaje que recibe del sistema de ayuda. ${ }^{4}$ Tras este apartado introductorio analizamos los distintos flujos de financiación externa que los países de la OCDE envían a ALC, entre los que se ubica la AOD. En el tercer apartado estudiamos la distribución geográfica de las ayudas entre los distintos países americanos. En cuarto lugar analizamos a los principales donantes (bilaterales y multilaterales) de la región. En el quinto apartado estudiamos los principales sectores e instrumentos de la AOD. Finalmente, concluimos revisando las principales implicaciones que la agenda de los ODM tiene para ALC en el sistema de AOD y ofrecemos propuestas de reforma para construir un sistema de AOD más eficiente, que compense la pérdida de volumen con incrementos en la calidad y en el impacto de los recursos.

Para un análisis cualitativo del impacto macroeconómico de la AOD en ALC, véase Tezanos et al. (2009). 


\section{AYUDA OFICIAL AL DESARROLLO Y OTRAS FUENTES DE FINANCIACIÓN EXTERNA DE AMÉRICA LATINA Y EL CARIBE}

Los flujos de financiación externa de ALC provenientes de los países de la OCDE han cambiado notablemente en el transcurso de los últimos 17 años; a la par, el volumen agregado del capital externo se incrementó 5.3 veces a lo largo del periodo (gráfico 1). De una parte, los flujos públicos de financiación han reducido considerablemente su proporción en el capital exterior de ALC. Así, los desembolsos netos de AOD representaban $18.1 \%$ del capital exterior en 1990, y esta cuota se redujo en 2007 a 4.5\%. Aún más destacada ha sido la caída experimentada por otros flujos oficiales de carácter no concesional (desde $28.9 \%$ hasta $1.5 \%$ ), habiéndose registrado un periodo con desembolsos negativos (2004-2006) como consecuencia de los fuertes repagos de créditos pasados, en un periodo en el que varios países de ALC aprovecharon la favorable coyuntura de los mercados financieros internacionales para emitir bonos con tipos de interés relativamente bajos y extinguir las deudas más caras contraídas con los países acreedores del Club de París y con la banca multilateral, lo que supuso un aumento significativo del servicio de la deuda oficial. La concesión de nuevos créditos desde 2005 explica el reciente repunte de estos flujos oficiales, que en 2007 registraban de nuevo desembolsos positivos.

De otra parte, los flujos privados de capital han sufrido fuertes fluctuaciones, acordes con los ciclos económicos latinoamericanos e internacionales. En primer lugar, la IED suponía $33.1 \%$ del capital externo en 1990, y este porcentaje aumentó hasta 43.8\% en

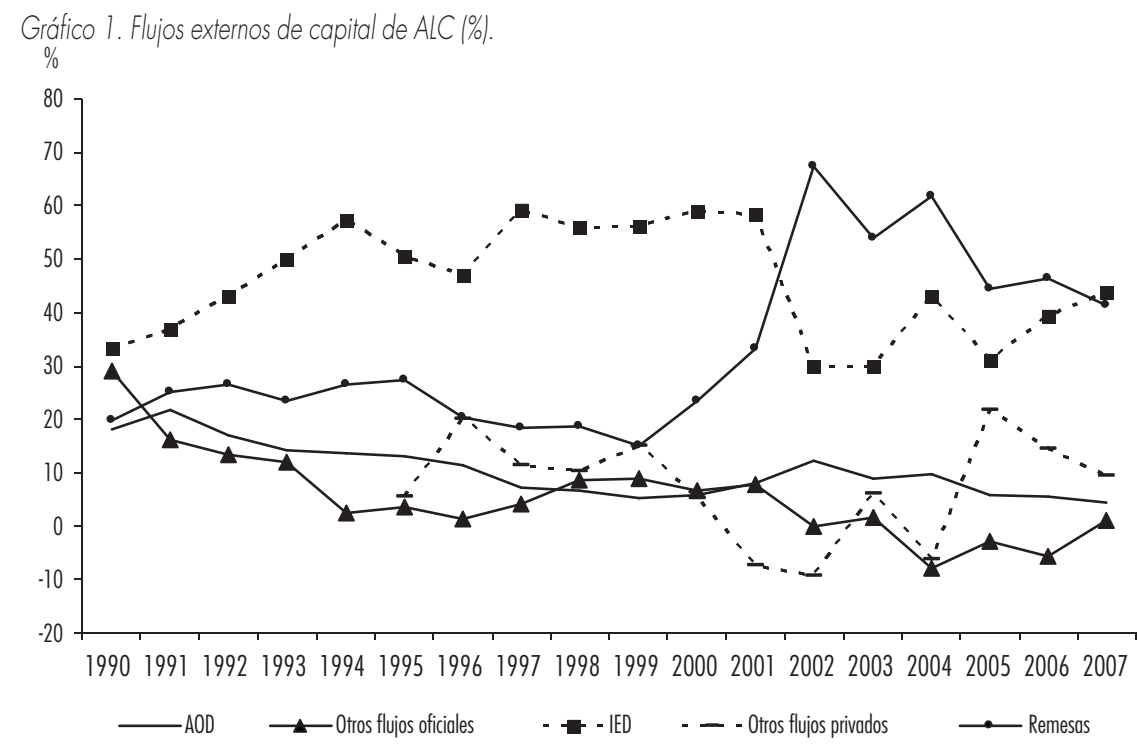


2007, concentrándose especialmente en cinco países: Brasil, México, Chile, Colombia y Argentina. En segundo lugar, el agregado de otros flujos privados (bancarios y no bancarios, incluyendo los recursos de las ONGD y las fundaciones privadas), representa en la actualidad 9.4\% del capital externo de la región, aunque se han revelado como flujos especialmente volátiles para la financiación del desarrollo. Finalmente, los flujos de remesas han incrementado formidablemente su participación, desde 5.7\% registrado en 1990 hasta 41.4\% en 2007, superando en importancia a la IED en los años 2002-2006. ${ }^{5}$

Atendiendo en concreto a los desembolsos netos de AOD recibidos por los países de ALC, la región ha visto disminuir las cuotas de ayuda global, una vez superados los programas de alivio de la deuda implementados en 1996, cuando la ayuda aumentó hasta el máximo de $13.4 \%$ debido a las importantes operaciones practicadas en Nicaragua y Bolivia (gráfico 2). Desde entonces, las cuotas de ayuda se han ido reduciendo paulatinamente hasta llegar a $6.5 \%$ en 2007. Aún mayor es el retroceso experimentado por ALC en la parte que recibió de las ayudas desembolsadas a los países de renta media (precisamente el colectivo de economías entre las que se ubican los países de ALC, exceptuando Haití), lo que revela una situación comparativamente más desventajosa que la del resto de países de similar nivel de desarrollo. ${ }^{6}$

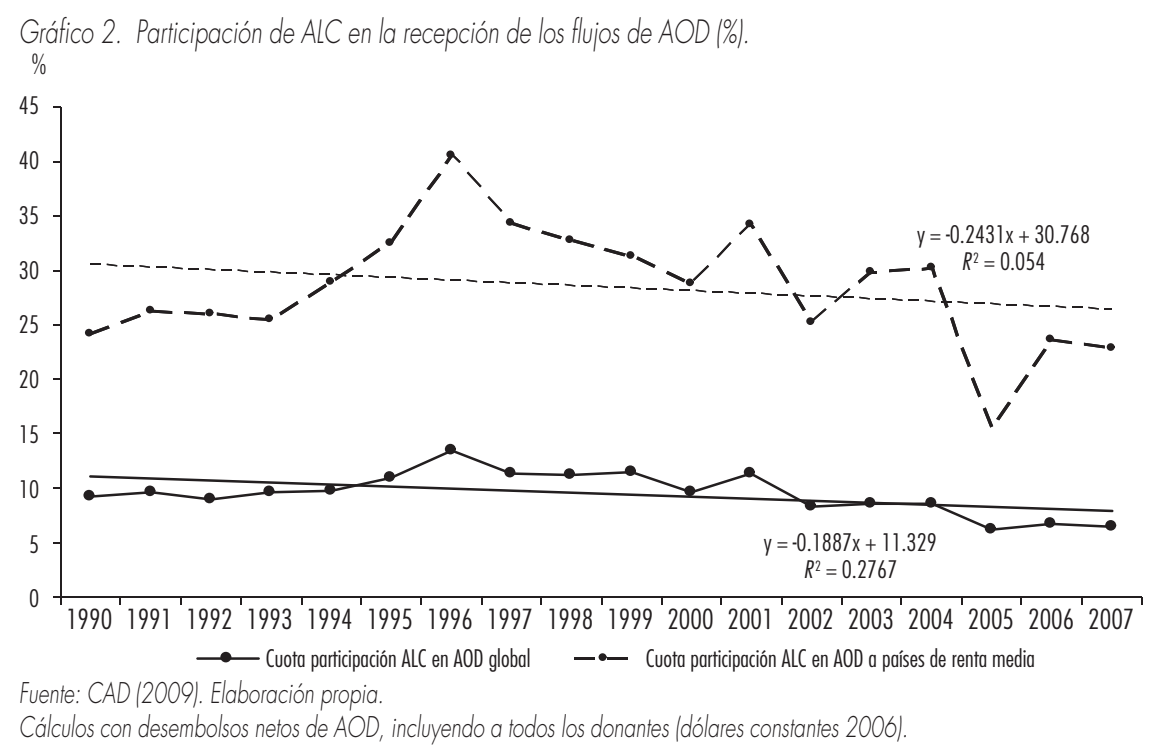

\footnotetext{
Los principales receptores de remesas son México, Brasil, Colombia, Guatemala y El Salvador.

Los valores mínimos de las cuotas de participación en la ayuda global y en la ayuda de los países de renta media se producen en 2005, como consecuencia de las fuertes operaciones de alivio de la deuda practicadas a otro país de renta media, Irak, que se ubicó como el primer receptor de AOD del mundo.
} 
Asimismo, distinguiendo el origen bilateral o multilateral de las ayudas, la participación de ALC en la recepción de ayuda de los países del CAD se ha reducido a un ritmo muy superior al experimentado en los flujos multilaterales hasta ubicarse en 2007 en la mitad de la cuota registrada en 1996 (gráfico 3). ${ }^{7}$ Por su parte, la ayuda multilateral, si bien experimentó un periodo de expansión entre 1995 y 1999 (asociado a los importantes créditos desembolsados por la AIF el Banco Mundial y el BID) se ha reducido desde entonces, permaneciendo desde 2004 en cuotas inferiores a $8 \%{ }^{8}$

Como consecuencia de esta merma en la recepción de los flujos globales de AOD, la ayuda supone actualmente una limitada aportación a la economía de ALC. De una parte, la ratio AOD/PNB se ha reducido desde 1990 , cuando la ayuda representaba $0.54 \%$ del PNB regional, frente a $0.22 \%$ que representó en 2007 (gráfico 4). De otra parte, las percepciones de AOD por persona han resultado especialmente volátiles, fluctuando a lo largo del periodo en el amplio intervalo de los 15.50 dólares (registrado en 1996

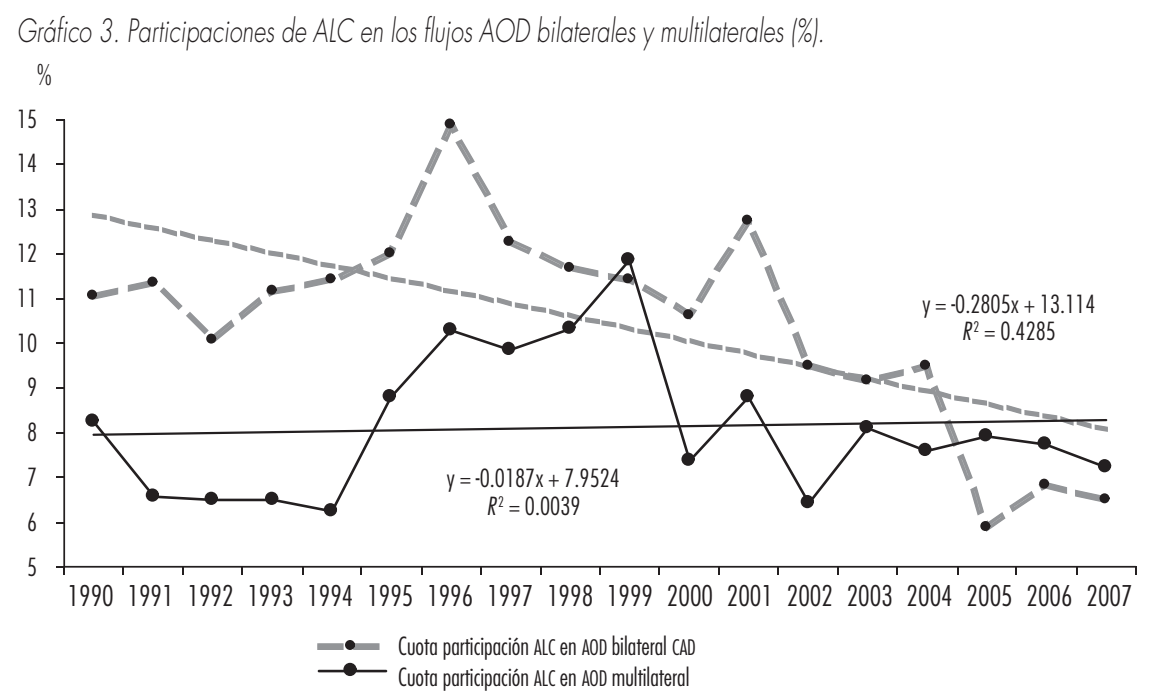

Fuente: CAD (2009). Elaboración propia.

Cuotas de participación de ALC en la recepción de los desembolsos netos de AOD de los países del CAD y de los Organismos Multilaterales (dólares constantes 2006).

7 Las ayudas del CAD a ALC han registrado dos puntos álgidos: en 1996 y en 2001, ambos como consecuencia de las importantes operaciones de alivio de la deuda practicadas a Nicaragua y Bolivia: Nicaragua se benefició de un alivio neto de la deuda de 492.5 millones de dólares en 1996, y de 786.23 millones en 2001; y Bolivia vio reducida su deuda en 157.3 millones en 1996 y en 234.49 millones en 2001.

8 De hecho, en el quinquenio 1995-1999, de la ayuda multilateral recibida por ALC 41.39\% consistió en créditos concesionales. Estas ayudas desempeñaron una función contracíclica relevante para paliar las crisis financieras de finales de los ańos noventa, en un contexto en el que los flujos privados de inversión se redujeron drásticamente. 
como consecuencia de las operaciones de alivio de la deuda antes comentadas) a los 9.44 dólares (registrado en 2000). Asimismo, si en la década de los noventa Nicaragua y Honduras se encontraron en algún ańo entre los 10 máximos receptores de ayuda del mundo (en 1996 y 1999, respectivamente), en lo que va del siglo XXI ningún país americano se ha ubicado en este listado.

\section{Gráfico 4. Evolución de los desembolsos de AOD per cápita y AOD/PNB a ALC.}

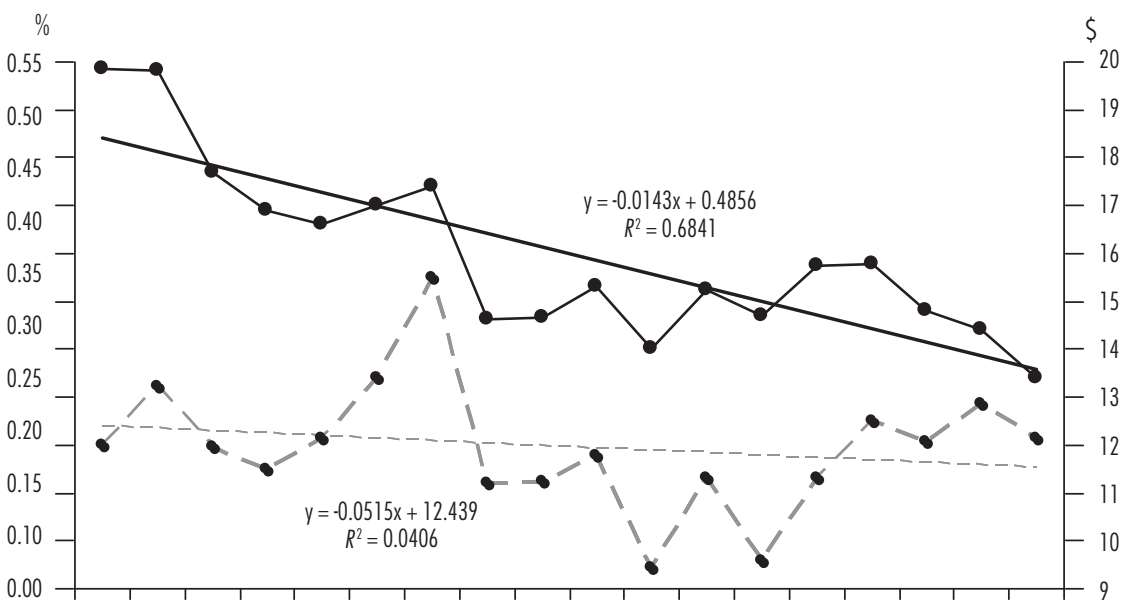

199019911992199319941995199619971998199920002001200220032004200520062007

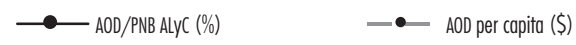

Fuente: CAD (2009) y Banco Mundial (2009). Elaboración propia.

AOD per cápita respecto de la población agregada de los países de ALC (dólares constantes 2006).

Ratio de AOD respecto del PNB agregado de los países de ALC.

Este proceso de paulatina reducción de lo que recibe ALC en el sistema de AOD se debe, en buena medida, a la puesta en práctica de la estrategia de los ODM en el año 2000. De este modo, el especial énfasis otorgado a los países más pobres está produciendo un modesto proceso de reasignación de la ayuda desde los PED con niveles de desarrollo relativamente más elevados (entre los que se encuentra la mayoría de países de ALC) hacia los países con menores niveles de desarrollo (Tezanos, 2010). Esta dinámica de reasignación de los recursos se ha visto suavizada por la tendencia alcista que experimentaron los desembolsos netos de ALC en el arranque del siglo XXI, los cuales superan el umbral de los 100 mil millones de dólares desde 2005 y han alcanzado la histórica cifra de casi 120 mil millones en $2008 .{ }^{9}$ Esto ha permitido aumentar las cuotas de ayuda

9 Si bien los desembolsos de AOD se redujeron en los años 2006 y 2007, se ha experimentado un importante incremento en 2008 (hasta alcanzarse los 119759 millones de dólares), coincidiendo con el arranque de la actual crisis financiera internacional. 
dirigidas a los países más pobres sin tener que reducir drásticamente los desembolsos dirigidos a los países de desarrollo intermedio. Así, los países de ingreso intermedio (renta media-baja y media-alta) han conseguido mantener (o reducir levemente) sus percepciones de ayuda per cápita, aun a pesar de haber disminuido las cuotas de ayuda que recibían de AOD global. En concreto, la región de ALC ha mantenido la recepción de AOD relativamente estable a lo largo del periodo (de más de 7500 millones de dólares al año, en términos constantes), de manera tal que en el septenio posterior a los ODM recibió una cantidad agregada de AOD ligeramente inferior a la recibida en el septenio anterior (48 892 millones de dólares, frente a 50576 millones). No obstante, el actual escenario de crisis económica mundial amenaza con hacer más "riguroso" el proceso de reasignación. Si la crisis menoscaba la "generosidad" de los países del CAD -actualmente acuciados por crecientes déficit fiscales para combatir la crisis dentro de sus fronteras-, una reducción de los desembolsos de AOD posicionará a los donantes ante un dilema que no habían afrontado en lo que va del siglo: avanzar en la reasignación de la ayuda a favor de los países más pobres, tal y como exige la estrategia ODM, pero esta vez a costa de reducir drásticamente los “dólares" - y no sólo las cuotas- de ayuda dirigidos a los países de renta media; o mantener inalterado el reparto de la ayuda, al menos hasta que se relaje la restricción presupuestaria -lo que resultaría en un incumplimiento manifiesto de la estrategia ODM-. Obviamente, ante este escenario de reasignación de la ayuda, los países de ALC pueden enfrentar una seria reducción tanto en el porcentaje que reciben de la AOD global como en los dólares de ayuda recibidos.

\section{DISTRIBUCIÓN GEOGRÁFICA DE LA AOD EN AMÉRICA LATINA Y EL CARIBE}

De acuerdo con el listado del CAD, la región de ALC cuenta con 32 países en desarrollo que son potenciales receptores de AOD. De éstos, tan sólo Haití pertenece al grupo de los "países menos adelantados", 11 son países de renta media-baja y los 20 restantes son países de renta media-alta (véase cuadro 1).

Como ya se dijo, el proceso de reasignación de la ayuda motivado por los ODM se ha traducido en ALC en una reducción modesta del volumen de ayuda agregada, y en un descenso mayor en las percepciones de ayuda por persona (cuadro 2). Así, si atendemos a un septenio antes y otro después de los ODM, veremos que en el periodo previo a la puesta en práctica de esta estrategia (1994-2000) ALC recibió un desembolso total de 50576 millones de dólares, lo que se correspondió con una percepción de 14.69 dólares per cápita. En cambio, en el septenio siguiente el volumen de AOD se redujo en casi 1700 millones de dólares, y las percepciones per cápita en casi dos dólares. De este modo, tan sólo nueve de los 32 países lograron incrementar sus percepciones de ayuda por habitante (entre los que destacan los incrementos de Granada, San Cristóbal y Nieves, Barbados, Nicaragua y Ecuador), todos ellos superiores a los 15 dólares adicionales por persona. Al tiempo, los 
países con mayores niveles de renta per cápita (Argentina, Chile, Uruguay y Costa Rica) vieron reducirse sus percepciones de ayuda por persona.

Cuadro 1. Países de ALC potenciales receptores de AOD

\begin{tabular}{|c|c|c|}
\hline Países menos desarrollados & Países de ingreso medio bajo & Países de ingreso medio alto \\
\hline & $\begin{array}{l}\text { PIB per cápita entre } 936 \text { y } 3705 \$ \\
\text { en } 2007\end{array}$ & $\begin{array}{l}\text { PIB per cápita entre } 3706 \text { y } 11455 \\
\$ \text { en } 2007\end{array}$ \\
\hline \multirow[t]{20}{*}{ Haití } & Bolivia & Antigua y Barbuda \\
\hline & Colombia & Argentina \\
\hline & República Dominicana & Barbados \\
\hline & Ecuador & Belice \\
\hline & El Salvador & Brasil \\
\hline & Guatemala & Chile \\
\hline & Guyana & Costa Rica \\
\hline & Honduras & Cuba \\
\hline & Nicaragua & Dominica \\
\hline & Paraguay & Granada \\
\hline & Perú & Jamaica \\
\hline & & México \\
\hline & & Panamá \\
\hline & & San Cristobal y Nieves \\
\hline & & Santa Lucía \\
\hline & & San Vicente y Las Granadinas \\
\hline & & Surinam \\
\hline & & Trinidad y Tobago \\
\hline & & Uruguay \\
\hline & & Venezuela \\
\hline
\end{tabular}

Los países de ALC con mayores cuotas de recepción en la AOD regional son Nicaragua, Bolivia, Colombia, Honduras, Perú, Haití y Guatemala (todos ellos países de renta media-baja, excepto Haití, y con cuotas superiores a 4\%). En cambio, en términos relativos a la población del receptor, los países que más ayuda per cápita reciben son los caribeños de menor tamaño, junto con Nicaragua, Honduras, Bolivia, Belice y Haití, confirmándose así un importante sesgo en la asignación de los recursos a favor de los países poblacionalmente más pequeños.

De acuerdo con la estrategia de cumplimiento universal de los ODM, la ayuda debería entregarse prioritariamente a los países que experimentan ritmos más rezagados de 
Cuadro 2. Participación de los países de ALC en el sistema de AOD

\begin{tabular}{|c|c|c|c|c|c|c|}
\hline & \multicolumn{2}{|c|}{ AOD (millones \$ $)^{11}$} & \multicolumn{2}{|c|}{ Cuota AOD $|\%|^{|2|}$} & \multicolumn{2}{|c|}{ AOD per cápita $\left(\left.\$\right|^{|3|}\right.$} \\
\hline & 1994-2000 & $2001-2007$ & $1994-2000$ & 2001-2007 & 1994-2000 & $2001-2007$ \\
\hline Total ALC & 50576.34 & 48892.54 & 100 & 100 & 14.69 & 12.90 \\
\hline Trinidad y Tobago & 169.14 & 3.27 & 0.33 & 0.01 & 18.88 & 0.31 \\
\hline Brasil & 1898.04 & 1495.04 & 3.75 & 3.06 & 1.63 & 1.17 \\
\hline México & 1298.92 & 1034.24 & 2.57 & 2.12 & 2.03 & 1.44 \\
\hline Venezuela & 354.84 & 455.19 & 0.70 & 0.93 & 2.18 & 2.50 \\
\hline Panamá & 250.55 & 59.14 & 0.50 & 0.12 & 12.95 & 3.04 \\
\hline Argentina & 850.19 & 835.85 & 1.68 & 1.71 & 3.44 & 3.13 \\
\hline Chile & 954.38 & 592.52 & 1.89 & 1.21 & 9.29 & 5.23 \\
\hline Uruguay & 329.58 & 147.42 & 0.65 & 0.30 & 14.56 & 6.36 \\
\hline Costa Rica & 188.86 & 193.95 & 0.37 & 0.40 & 7.61 & 6.48 \\
\hline Cuba & 551.20 & 613.46 & 1.09 & 1.25 & 7.14 & 7.80 \\
\hline Paraguay & 705.51 & 431.42 & 1.39 & 0.88 & 20.16 & 10.64 \\
\hline Rep. Dominicana & 865.60 & 737.12 & 1.71 & 1.51 & 14.81 & 11.38 \\
\hline Colombia & 1567.64 & 4779.66 & 3.10 & 9.78 & 5.61 & 15.37 \\
\hline Perú & 3263.84 & 3349.00 & 6.45 & 6.85 & 18.93 & 17.84 \\
\hline Jamaica & 465.90 & 334.72 & 0.92 & 0.68 & 26.67 & 18.15 \\
\hline Guatemala & 2034.52 & 2286.81 & 4.02 & 4.68 & 27.61 & 26.22 \\
\hline Barbados & 27.65 & 65.38 & 0.05 & 0.13 & 13.93 & 32.09 \\
\hline El Salvador & 2038.87 & 1.527 .80 & 4.03 & 3.12 & 50.16 & 33.53 \\
\hline Ecuador & 1601.93 & 1.508 .69 & 3.17 & 3.09 & 19.54 & 35.72 \\
\hline Haití & 3634.68 & 2.694 .37 & 7.19 & 5.51 & 64.76 & 41.50 \\
\hline Belice & 210.93 & 125.23 & 0.42 & 0.26 & 131.23 & 64.93 \\
\hline Antigua y Barbuda & 54.54 & 48.73 & 0.11 & 0.10 & 106.98 & 86.24 \\
\hline Bolivia & 5457.18 & 5778.22 & 10.79 & 11.82 & 100.07 & 92.47 \\
\hline Honduras & 3572.01 & 4332.66 & 7.06 & 8.86 & 86.86 & 92.91 \\
\hline Sta. Lucía & 217.61 & 111.31 & 0.43 & 0.23 & 210.52 & 98.31 \\
\hline Surinam & 585.58 & 333.90 & 1.16 & 0.68 & 198.14 & 105.32 \\
\hline $\begin{array}{l}\text { San Vicente y Las } \\
\text { Granadinas }\end{array}$ & 153.13 & 103.42 & 0.30 & 0.21 & 192.16 & 123.88 \\
\hline Nicaragua & 5385.12 & 6628.05 & 10.65 & 13.56 & 159.01 & 176.34 \\
\hline San Cristóbal y Nieves & 47.63 & 60.30 & 0.09 & 0.12 & 164.82 & 183.89 \\
\hline Guyana & 1112.18 & 953.44 & 2.20 & 1.95 & 215.53 & 184.57 \\
\hline Granada & 97.82 & 156.85 & 0.19 & 0.32 & 140.82 & 211.10 \\
\hline Dominica & 174.28 & 163.39 & 0.34 & 0.33 & 345.17 & 325.93 \\
\hline
\end{tabular}

Fuente: CAD (2009). Elaboración propia.

(II) Desembolsos netos de AOD acumulados por periodo (dólares constantes 2006).

(2) Cuotas de recepción en el acumulado de AOD desembolsada a ALC por periodo (dólares constantes 2006).

${ }^{13}$ AOD per cápita: ratio de AOD neta agregada por periodo (dólares constantes 2006) respecto de población agregada.

reducción de la pobreza e, incluso, a aquellos que han sufrido regresiones. En cambio, los países que se han revelado más exitosos en reducir la pobreza deberían recibir cantidades proporcionalmente menores de ayuda. Pues bien, en lo que va del siglo XXI no se ha producido una relación directamente proporcional entre la ayuda per cápita y la tasa de variación de la pobreza (véase el coeficiente negativo de la recta de regresión y el 
prácticamente nulo grado de asociación que recoge el coeficiente $R^{2}$ del gráfico 5). En realidad, la distribución de la ayuda per cápita ha tendido a beneficiar a los países que han experimentado tasas de variación de la pobreza próximas a cero (es decir, países estancados en reducir la pobreza) y no tanto a los países que han experimentado importantes retrocesos (los que se ubican a la derecha del cero en el eje horizontal del gráfico, exceptuando Bolivia, como son los casos de Guatemala, Perú, República Dominicana, Colombia, Paraguay, Venezuela y Argentina), ni tampoco a los que han logrado reducir considerablemente la pobreza (los que se ubican a la izquierda del cero). Más en concreto, los ocho países cuya tasa de pobreza aumentó han recibido una atención modesta por parte de los donantes (desde luego, no la que exigiría el cumplimiento de los ODM), con percepciones de AOD per cápita que discurren en el amplio intervalo de los 2.5 dólares de Venezuela y los 92.5 dólares de Bolivia. Asimismo, los países exitosos en reducir la pobreza han recibido cantidades muy similares de ayuda (de hecho, los dos países con mayores recepciones de ayuda per cápita se encuentran entre los que han conseguido reducir la pobreza: Guyana y, en menor medida, Nicaragua).

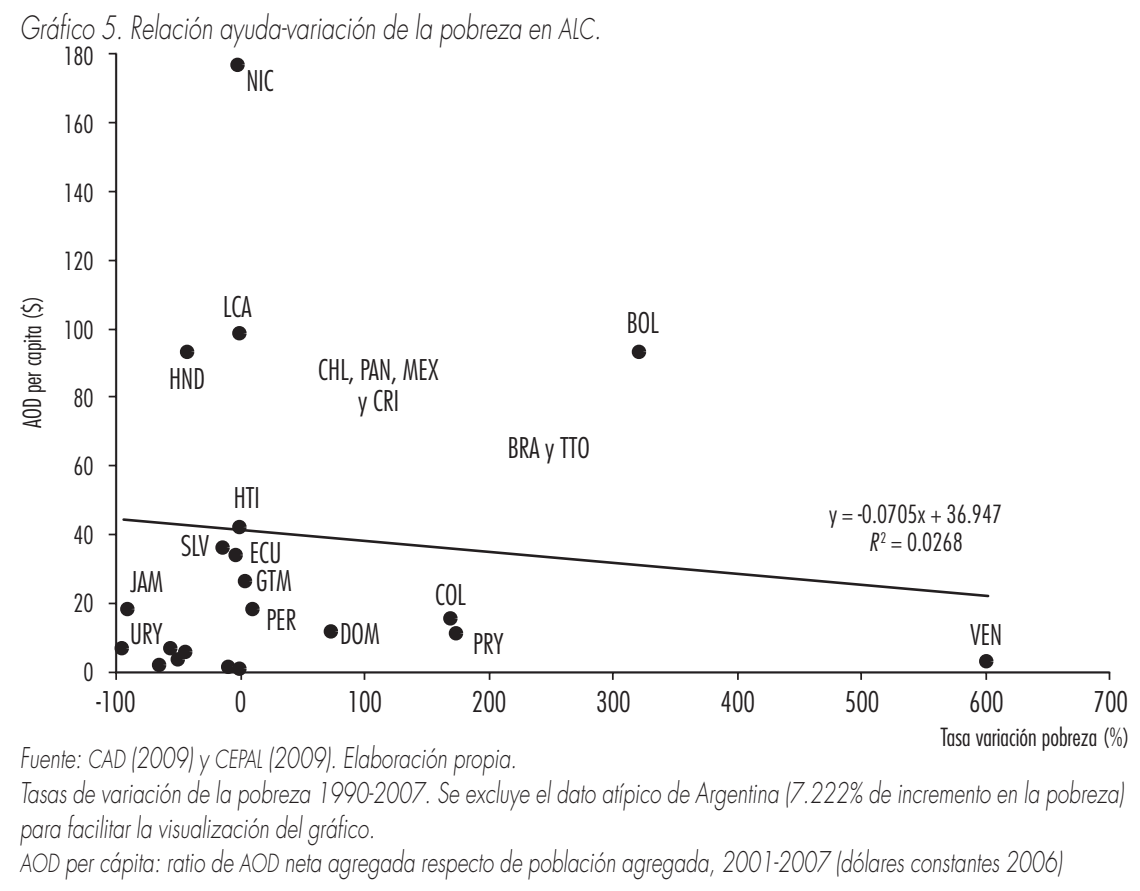

Conviene valorar finalmente si la agenda de los ODM está mejorando el grado de "progresividad" alcanzado por el mapa de la ayuda en el interior de ALC, antes y después 
de la aprobación de los ODM. Dos indicadores especialmente útiles a este respecto son las curvas de concentración relativa y los indices de Suits, que permiten evaluar la capacidad redistributiva de la ayuda en función de la proporción que representan los países socios en la población pobre regional. ${ }^{10}$ De acuerdo con este análisis, el mapamundi de la ayuda se considera progresivo siempre y cuando se apoye de manera prioritaria y más que proporcionalmente a los países relativamente más necesitados, evaluándose dichos niveles de necesidad mediante indicadores de ingreso per cápita y de proporcionalidad en la pobreza regional. Por consiguiente, un mapa de asignación progresivo contribuye a redistribuir la renta a escala internacional y a reducir las desigualdades.

Leyendo de izquierda a derecha en la caja (gráfico 6) se ubican los países receptores de ayuda ordenados ascendentemente por niveles de renta per cápita. Cada segmento de la curva se corresponde con un PED, siendo su longitud proporcional a la participación de cada país en la ayuda que se recibe y en la pobreza regional. Más concretamente, la distancia vertical de cada segmento representa la participación de un país en la recepción de AOD bilateral y multilateral agregada, y la distancia horizontal representa la proporción de ese país en la población pobre regional (en realidad, la población pobre muestral). Por lo tanto, en el caso de asignaciones con un claro "enfoque anti-pobreza" -es decir, donde la ayuda se destina prioritariamente a los países más pobres-, la curva de concentración adoptará inicialmente una pendiente positiva y mayor de 45 grados, discurriendo por encima de la diagonal; posteriormente, la pendiente de la curva tenderá progresivamente a cero a medida que se avance hacia las últimas posiciones de la lista -es decir, hacia los países relativamente más ricos-. Por su parte, el índice de Suits asigna un valor numérico a la distribución de la curva de concentración, pudiendo tomar valores en el intervalo entre -1 (cuando toda la ayuda se destina al país más pobre) y +1 (cuando toda la ayuda se destina al receptor relativamente más rico). Respectivamente, estas dos situaciones extremas trazarían los siguientes "segmentos" de concentración: el eje de ordenadas izquierdo (-1); el segmento del eje de abscisas inferior y el segmento del eje de ordenadas derecho $(+1) \cdot{ }^{11}$

Pues bien, la asignación de la ayuda entre los países de ALC ha sido marcadamente progresiva, y además ha tendido a mejorar entre el bienio 1994-1995 y el bienio 20062007, tal y como reflejan los índices de Suits (que han pasado de -0.26, a -0.37). De este modo, ambas curvas de concentración de la ayuda discurren en su primer tramo por encima de la diagonal, debido a las asignaciones de ayuda más que proporcionales a los países de menores rentas. Asimismo, las curvas se tornan marcadamente más horizontales en el tramo final del gráfico, donde se ubican los países latinoamericanos de mayores

10 Véase Tezanos (2008: cap. 3) para una explicación detallada de los aspectos metodológicos de estos indicadores.

11 Un valor del índice igual a 0 puede corresponder tanto a una asignación directamente proporcional a la población pobre del país receptor -discurriendo a lo largo de la diagonal de la caja-, como a una asignación en la que un primer reparto progresivo (regresivo) de la ayuda entre los países más pobres sea contrarrestado por un segundo tramo de asignación más regresivo (progresivo) entre los países de renta media, compensándose dichos valores en el índice de Suits. 
rentas, que reciben cuotas menores de AOD. Más en concreto, en el bienio más reciente las cuotas de ayuda percibidas por siete de los 10 países con menores niveles de renta per cápita de la muestra (Haití, Nicaragua, Guyana, Honduras, Bolivia, Guatemala y Colombia) son mayores que su presencia en la pobreza regional, al tiempo que los países con mayores niveles de ingresos per cápita (como Brasil, Venezuela, México y Argentina) reciben cuotas de ayuda inferiores a su presencia en la pobreza, como corresponde a un reparto progresivo de los recursos. En cambio -cabe alertar-, otros países de ingresos relativamente bajos, como Paraguay, Ecuador y El Salvador, participan menos que proporcionalmente en la ayuda que en la pobreza.

En suma, los 10 países con menores niveles de ingreso - de los 23 países analizadosconcentraron $80 \%$ de las ayudas desembolsadas en 2006-2007, aun a pesar de representar $42.34 \%$ de la población pobre de la muestra. Con todo, no parece inadecuado

Gráfico 6. Curva de concentración de la AOD a ALC, 1994-1995 y 2006-2007.

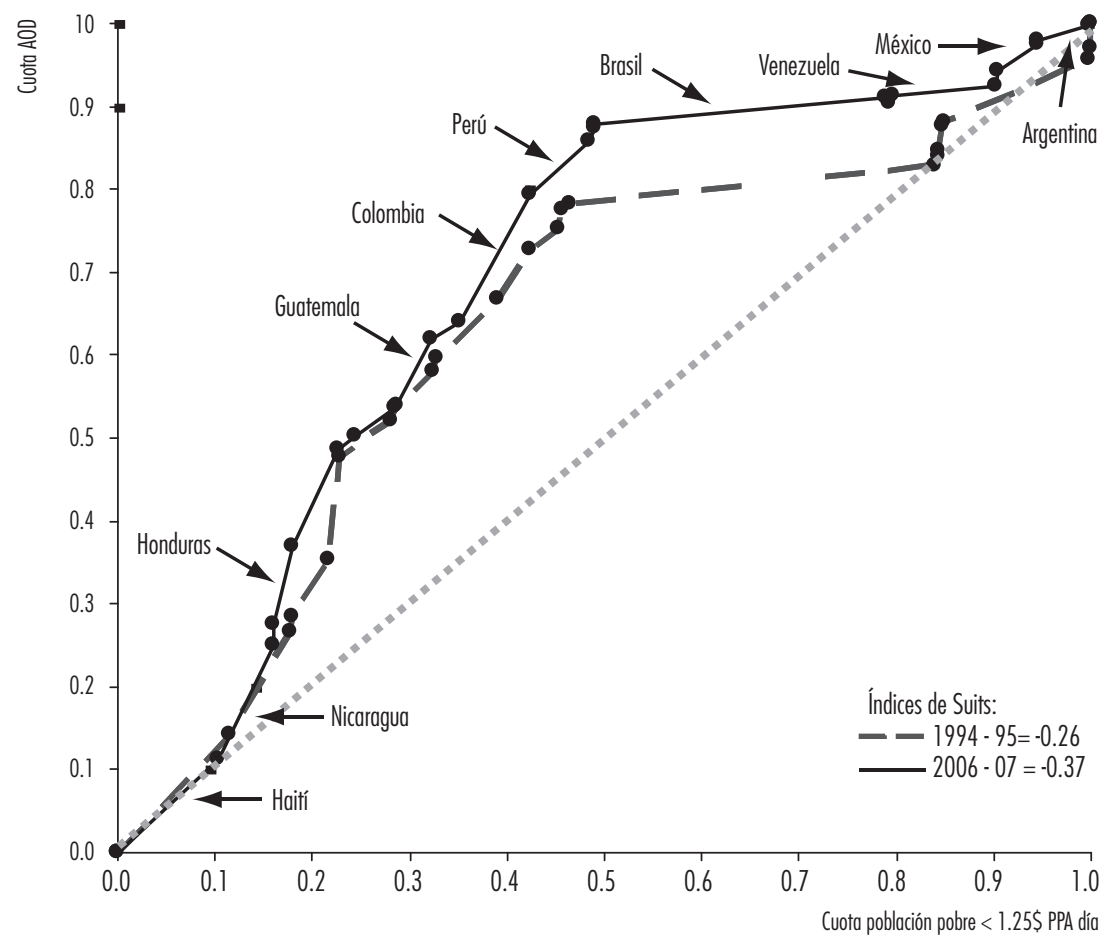

Fuente: Banco Mundial (2009), CAD (2009) y CEPAL (2009). Elaboración propia.

Desembolsos netos de AOD de todos los donantes (dólares constantes 2006). Muestra de 23 países: Argentina, Bolivia, Brasil, Chile, Colombia, Costa Rica, Ecuador, El Salvador, Guatemala, Guyana, Haití, Honduras, Jamaica, México, Nicaragua, Panamá, Paraguay, Perú, Republica Dominicana, Santa Lucía, Trinidad y Tobago, Uruguay y Venezuela. 
afirmar que los ODM, tras casi nueve años en vigor, están generando una alteración correcta en el mapa de la ayuda de ALC.

\section{DONANTES DE AMÉRICA LATINA Y EL CARIBE}

En el septenio 2001-2007 los países de ALC han recibido ayudas de los 22 países donantes del CAD (que aportan casi tres cuartas partes de la AOD), un buen número de organismos multilaterales de desarrollo (que aportan un cuarto de los recursos), y de varios países donantes que no pertenecen al CAD (con apenas un punto porcentual de aportación) (cuadro 3). ${ }^{12} \mathrm{~A}$ pesar del elevado número de donantes, la ayuda se genera prácticamente por ocho países del CAD (EUA, España, Alemania, Japón, Canadá, Holanda, Francia y Suecia) y tres organismos multilaterales (Comisión Europea, AIF y BID), que en conjunto aportaron $84.3 \%$ de las ayudas (cada uno de ellos con desembolsos acumulados de AOD superiores a los mil millones de dólares). Entre estos donantes, EUA es el principal financiador de la región, seguido de España (si bien este último es el que más está aumentando sus desembolsos de AOD). ${ }^{13}$

Si bien las cifras anteriores revelan quiénes son los principales donantes de la región, no informan de la paulatina pérdida en la recepción de ayuda de ALC en el presupuesto global de AOD, que ha retrocedido en 3.25 puntos porcentuales entre ambos periodos (cuadro 4). Atendiendo a la importancia de ALC en el presupuesto de cada donante, destaca la prioridad concedida a esta región por Espańa -a la que destina $41.6 \%$ de sus ayudas-y, en menor medida, por Canadá -con 12.7\%-. El resto de donantes otorgan una importancia comparativamente menor a ALC, con cuotas inferiores a 10\%. Asimismo, tan sólo dos donantes del CAD (Canadá y Francia) han incrementado la cuota para ALC en sus respectivos presupuestos de AOD, mientras que el resto de donantes han reducido dichos porcentajes, siendo especialmente severos los recortes practicados por Reino Unido, Italia y Holanda. En este sentido, de los 10 principales donantes a la región, las estrategias de cooperación de tres de ellos (Reino Unido, Suecia y Alemania) contemplan una retirada paulatina, y otros cuatro (Japón, Francia, Holanda e Italia) conceden una atención muy limitada a ALC en la definición de sus planes estratégicos de cooperación.

Con respecto a la financiación multilateral, los desembolsos acumulados de estas ayudas han rondado los 12 mil millones de dólares en ambos periodos, siendo la Comisión Europea el principal financiador regional (con una aportación superior a $10 \%$ de las ayudas), seguida, a gran distancia, por la AIF y el BID (de nuevo, cuadro 3). Esta situación de parcial estancamiento contrasta con la reducción de la presencia de

12 Asimismo, en los últimos años se han fortalecido las experiencias de "cooperación horizontal" entre los países del continente. No obstante, estos flujos de ayuda no se computan como AOD, de acuerdo con los criterios del CAD. Véase a este respecto el reciente informe sobre cooperación sur-sur en Iberoamérica: Xalma (2009).

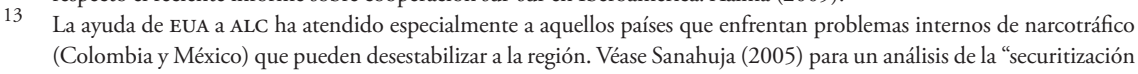
de la ayuda”. 
Sergio Tezanos Vázquez y Aitor Martínez de la Cueva Astigarraga

Cuadro 3. Aportaciones de AOD a ALC por donante.

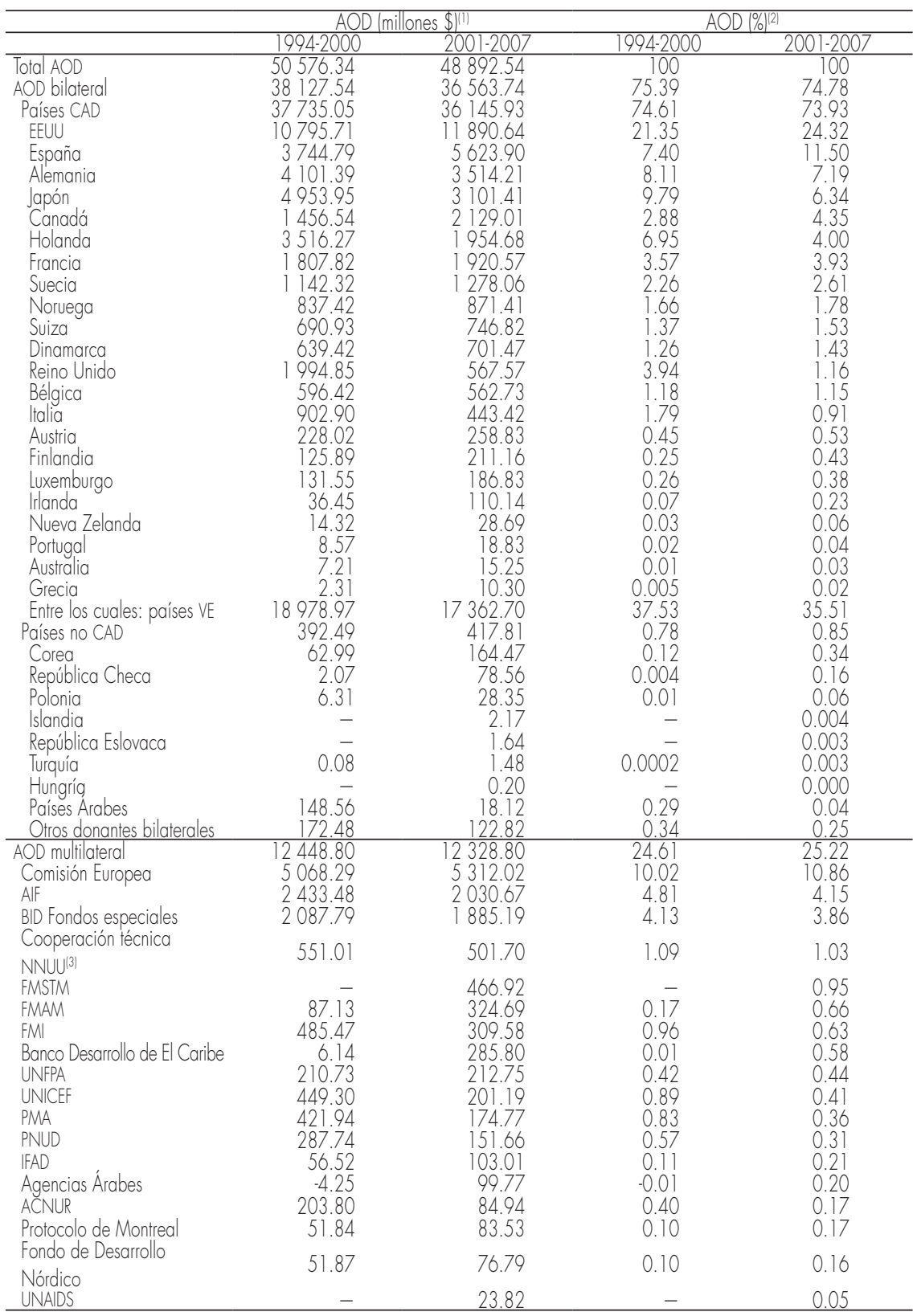

Fuente: CAD (2009). Elaboración propia.

(II) Desembolsos netos de AOD acumulados por periodo (dólares constantes 2006).

${ }^{(2)}$ Cuota de participación de ALC en la recepción del desembolso neto acumulado de AOD por periodo.

(3) UNTA agrupa la asistencia técnica realizada por las agencias especializadas de la ONU con cargo a sus presupuestos regulares (principalmente OMS, UNESCO, FAO, OIT y ONUDII). 
ALC en los presupuestos de AOD de prácticamente la totalidad de los organismos multilaterales (exceptuando al FMI y a aquellos organismos de carácter estrictamente regional), siendo especialmente acusada la caída en los presupuestos del principal financiador multilateral, la Comisión Europea (cuadro 4). ${ }^{14}$ Sin embargo, ALC continúa siendo la región del mundo en desarrollo con mayor número de organismos multilaterales de carácter regional, y la única que cuenta con un banco de desarrollo multilateral para cada subregión americana (SELA, 2005).

Cuadro 4. Participación de ALC en la recepción de AOD de los principales donantes de la región (\%).

\begin{tabular}{lccc}
\hline & $1994-2000$ & $2001-2007$ & Variación (p.p.ll) \\
\hline Total AOD & 11.04 & 7.79 & -3.25 \\
AOD bilateral & 11.89 & 7.86 & -4.04 \\
Países CAD & 12.03 & 8.19 & -3.84 \\
España & 43.26 & 41.58 & -1.67 \\
Canadá & 10.62 & 12.56 & 1.94 \\
Estados Unidos & 19.57 & 9.86 & -9.71 \\
Alemania & 13.39 & 8.99 & -4.40 \\
Suecia & 11.14 & 8.25 & -2.89 \\
Holanda & 17.13 & 7.72 & -9.41 \\
Japón & 9.09 & 6.39 & -2.70 \\
Italia & 11.72 & 4.59 & -7.13 \\
Francia & 4.15 & 4.55 & 0.41 \\
Reino Unido & 9.62 & 1.38 & -8.24 \\
Entre los cuales: países UE & 11.54 & 7.83 & -3.71 \\
Países no CAD & 5.76 & 1.75 & -4.01 \\
AOD multilateral & 9.17 & 7.68 & -1.49 \\
BID Fondos especiales & 100.00 & 100.00 & 0.00 \\
Cooperación técnica NNUU & 17.08 & 14.01 & -3.07 \\
FMI & 11.23 & 13.35 & 2.12 \\
UNFPA & 12.53 & 10.88 & -1.64 \\
FMSTM & - & 10.06 & - \\
Comisión Europea & 11.32 & 8.79 & -2.53 \\
PMA & 8.60 & 6.13 & -2.47 \\
PNUD & 6.26 & 5.58 & -0.68 \\
AlF & 5.74 & 4.23 & -1.51 \\
UNICEF & 8.46 & 3.78 & -4.68 \\
\hline
\end{tabular}

Fuente: CAD (2009). Elaboración propia.

Promedios por periodo del porcentaje de participación de ALC en la recepción de los desembolsos netos de AOD de los principales donantes (dólares constantes 2006).

(1) Puntos porcentuales de variación.

14 Véase Sanahuja (2008) para un detallado informe de la cooperación europea con América Latina. 
Finalmente, conviene señalar que, en conjunto, la ayuda desembolsada a ALC por los distintos donantes ha resultado ser excesivamente fragmentada y volátil, lo que puede haber menoscabado la eficacia de las actuaciones (Tezanos et al., 2009). De una parte, el índice de concentración de la ayuda revela un excesivo fraccionamiento de los recursos entre los numerosos donantes presentes en cada país, si bien la concentración ha tendido a mejorar -muy levemente- a lo largo del periodo analizado (cuadro 5). ${ }^{15}$ Esta fragmentación sería, no obstante, aún mayor si no fuera por la parcial concentración de las ayudas en 11 donantes (bilaterales y multilaterales) que aportan más de cuatro quintos de los recursos. De otra parte, la ayuda ha sido especialmente volátil para los países de ALC, y esta volatilidad ha tendido a aumentar entre los dos septenios estudiados. Por lo tanto, en la medida en que en los últimos años se ha producido una retirada de donantes bilaterales de ALC se ha aminorado el problema de la fragmentación, si bien a costa de incrementar la volatilidad de los recursos.

Cuadro 5. Volatilidad y fragmentación de la ayuda en ALC

\begin{tabular}{lcc}
\hline & Índice fragmentación ayuda ${ }^{(1)}$ & ${\text { Coeficiente variación ayuda }{ }^{(2)}}^{1994-2000}$ \\
$2001-2007$ & 3.30 & $17.82 \%$ \\
\hline
\end{tabular}

Fuente: CAD (2009). Elaboración propia. Muestra de 32 países de ALC.

(II) Índice Hirschman-Herfindal construido mediante la suma de los cuadrados del tamaño relativo de la ayuda otorgada por los donantes de cada país. Valores por periodos calculados mediante medias geométricas.

${ }^{122}$ Coeficiente de variación de Pearson respecto de las cuotas de AOD/PIB de cada país. Valores por periodos calculados mediante medias geométricas.

\section{SECTORES E INSTRUMENTOS DE DESTINO DE AOD}

El grueso de la AOD desembolsada a ALC se ha destinado a financiar al sector de "infraestructura y servicios sociales”, que supone algo más de $45 \%$ de las ayudas (cuadro 6). Dentro de este sector general, los subsectores de "otra infraestructura y servicios sociales" (entre la que destaca el control de narcóticos), "gobierno y sociedad civil" y "educación” acaparan el grueso de los recursos. ${ }^{16}$

En segundo lugar destacan las "operaciones de alivio de la deuda", que supusieron casi $11 \%$ de las ayudas, entre las cuales las más importantes fueron para Nicaragua (en

15 El índice Hirschman-Herfindal utilizado toma valores entre 0 (máxima fragmentación de la ayuda) a 10000 (nula fragmentación).

16 El subsector "otra infraestructura y servicios sociales" incluye la provisión de servicios sociales, las políticas de empleo y vivienda, la generación de capacidad estadística, la mitigación social del viH/sida y el control de narcóticos, siendo precisamente este último el que acapara el grueso de los recursos (principalmente financiado por EUA como parte de su estrategia de seguridad regional). 
2004), Honduras (2006), Bolivia (2006) y Guatemala (2006). En tercer lugar se ubican las ayudas destinadas a fortalecer los "sectores productivos", que representaron $9.6 \%$ de los recursos, concentrándose especialmente en el sector de agricultura, pesca y silvicultura. En cuarto lugar destacan las ayudas "multisectoriales", no tanto por la importancia de las acciones medioambientales $(3.2 \%)$, como por la preponderancia de otras intervenciones multisectoriales (desarrollo y gestión urbana, desarrollo rural, educación mul-

Cuadro 6. Sectores de destino de la AOD a ALC

\begin{tabular}{|c|c|c|}
\hline & $\mathrm{AOD}$ (millones $\$$ (1) $^{11}$ & $A O D(\%)^{22}$ \\
\hline Total AOD bruta & 46195.16 & 100 \\
\hline Total sector imputable $(1+\|+||++\mid V)$ & 31486.83 & 68.16 \\
\hline 1. Infraestructura y servicios sociales & 19426.27 & 42.05 \\
\hline 1.1. Educación & 3512.56 & 7.60 \\
\hline 1.2. Salud & 1804.88 & 3.91 \\
\hline 1.3. Población y salud reproductiva & 1709.16 & 3.70 \\
\hline 1.4. Abastecimiento de agua y saneamiento & 1559.84 & 3.38 \\
\hline 1.5. Gobierno y sociedad civil & 4589.07 & 9.93 \\
\hline 1.6. Otras infraestructuras y servicios sociales & 6250.76 & 13.53 \\
\hline II. Infraestructura económica & 3325.44 & 7.20 \\
\hline 11. 1. Transporte y almacenaje & 690.73 & 1.50 \\
\hline 11.2. Comunicaciones & 951.59 & 2.06 \\
\hline 11.3. Energía & 393.42 & 0.85 \\
\hline 11.4. Servicios bancarios y financieros & 926.15 & 2.00 \\
\hline 11.5. Negocios y otros servicios & 363.54 & 0.79 \\
\hline III. Sectores productivos & 4417.97 & 9.56 \\
\hline III. I. Agricultura, silvicultura y pesca & 2994.08 & 6.48 \\
\hline III.2. Industria, minería y construcción & 775.30 & 1.68 \\
\hline III.3. Políticas y regulaciones comerciales & 574.74 & 1.24 \\
\hline III.4. Turismo & 73.85 & 0.16 \\
\hline IV Multisectorial & 4317.14 & 9.35 \\
\hline IV. 1. Protección del medio ambiente & 1462.25 & 3.17 \\
\hline IV. 3. Otros & 2854.89 & 6.18 \\
\hline Ayuda programática & 2334.62 & 5.05 \\
\hline Apoyo presupuestario general & 791.25 & 1.71 \\
\hline Ayuda alimentaria / seguridad alimentaria & 1414.44 & 3.06 \\
\hline Ayuda otros productos básicos & 128.93 & 0.28 \\
\hline Alivia de la deuda & 5006.55 & 10.84 \\
\hline Ayuda humanitaria & 1983.36 & 4.29 \\
\hline Costes administrativos de los donantes & 163.25 & 0.35 \\
\hline Apoyo a ONGD & 860.88 & 1.86 \\
\hline Refugiados en países donantes & 300.52 & 0.65 \\
\hline Sin asignar / sin especificar & 4059.15 & 8.79 \\
\hline
\end{tabular}

Fuente: CAD (2009). Elaboración propia.

(11) Desembolsos brutos de AOD acumulados en el periodo 2002-2007 (dólares constantes 2006). Todos los donantes.

${ }^{12)}$ Cuota por sector en el desembolso bruto acumulado de AOD por periodo (dólares constantes 2006). Todos los donantes. 
tisectorial e investigación para el desarrollo), que en total aportaron 9.3\% de las ayudas. En quinto lugar destaca la ayuda programática (apoyo presupuestario general, políticas de ayuda y seguridad alimentaria, y ayuda para productos básicos), que supone $5 \%$ de las ayudas a ALC. Dado el nivel de desarrollo relativamente elevado de la región, y la capacidad de gestión de sus gobiernos, esta modalidad de ayuda ha ido cobrando mayor protagonismo, si bien destaca que ALC no sea una de las regiones del mundo en desarrollo con mayor porcentaje de ayuda programática. ${ }^{17}$ Finalmente, otros sectores de destino de menor importancia relativa son la "infraestructura económica" y la "ayuda humanitaria” (fuertemente condicionadas por la presencia de desastres naturales en la región).

Conviene señalar que la distribución sectorial de la AOD no encaja plenamente con los ámbitos de desarrollo en los que la región se encuentra más rezagada en la estrategia de los ODM. Si bien ALC -en conjunto- se encuentra encaminada a lograr buena parte de ellos, el desempeño en los 38 indicadores correspondientes a los siete primeros ODM (precisamente aquellas metas que permiten evaluar el resultado de las políticas de desarrollo acometidas por los PED) no es totalmente satisfactorio. Así, la región registró retrocesos en dos de los indicadores relativos a la sostenibilidad del medio ambiente (proporción de superficie cubierta por bosques y emisiones de dióxido de carbono) y un acusado estancamiento en otros tres indicadores (proporción de la población ocupada que trabaja por cuenta propia, tasa de alfabetización de los jóvenes y necesidades insatisfechas en materia de planificación familiar) (Tezanos y Domínguez, 2009). En este contexto, resulta especialmente preocupante constatar que la distribución sectorial de la ayuda no atiende prioritariamente a estos sectores (especialmente en el caso de la protección medioambiental, las políticas de población y salud reproductiva, y las políticas de empleo). ${ }^{18}$

Respecto a las modalidades e instrumentos de AOD que ha recibido ALC (cuadro 7), la ayuda no reembolsable (donaciones) ha tenido un importante incremento entre el periodo 1994-2000 y el periodo 2001-2007, que es superior a los 13 mil millones de dólares, principalmente por la ampliación de las operaciones de alivio de la deuda y de la cooperación técnica. De este modo, esta última se consagra como la modalidad más importante de ayuda, con una cuota en el septenio reciente de $45 \%$. A pesar del aumento en las donaciones, el desembolso neto de AOD se ha visto aminorado en el tiempo, como consecuencia de la disminución de la ayuda reembolsable (préstamos): la concesión de créditos se redujo en más de cuatro mil millones de dólares (aunque siguen representando $26.2 \%$ de las ayudas), a la par que se incrementaba en 682 millones la amortización de préstamos y se compensaban más de 10 mil millones del principal de las deudas condonadas. Como consecuencia de esta paulatina reducción del principal de los préstamos AOD, se está reduciendo ligeramente el importe de los intereses pagados por ALC

17 Este porcentaje asciende, para el mismo periodo, a 8.4\% en el caso de África y a 8.3\% en Oceanía.

18 Las políticas de empleo se contabilizan en el sector "otras infraestructuras y servicios sociales". 
Cuadro 7. Instrumentos y modalidades de AOD a ALC.

\begin{tabular}{|c|c|c|c|c|}
\hline & \multicolumn{2}{|c|}{ AOD /millones \$ ${ }^{i !}$} & \multicolumn{2}{|c|}{$A O D(\%)^{|2|}$} \\
\hline & $1994-2000$ & $2001-2007$ & $1994-2000$ & $2001-2007$ \\
\hline TOTAL AOD neta & 50576.34 & 48892.54 & 100 & 100 \\
\hline Total donaciones & 45328.16 & 58.338 .74 & 89.62 & 119.32 \\
\hline \multicolumn{5}{|l|}{ Entre otras: } \\
\hline Condonaciones deuda & 2848.59 & 13899.93 & 5.63 & 28.43 \\
\hline Ayuda alimentaria & 1667.10 & 1778.25 & 3.30 & 3.64 \\
\hline Ayuda humanitaria & 2116.35 & 2317.70 & 4.18 & 4.74 \\
\hline Cooperación técnica & 19781.45 & 21993.21 & 39.11 & 44.98 \\
\hline Total préstamos netos & 5248.18 & -9446.20 & 10.38 & -19.32 \\
\hline \multicolumn{5}{|l|}{ Entre otros: } \\
\hline Préstamos brutos & 17055.64 & 12826.90 & 33.72 & 26.23 \\
\hline Reembolsos de préstamos & -10757.95 & -11440.42 & -21.27 & -23.40 \\
\hline Renegociación de deuda & 454.48 & 161.50 & 0.90 & 0.33 \\
\hline $\begin{array}{l}\text { Ajustes contables por operaciones alivio } \\
\text { deuda }\end{array}$ & -1026.14 & -10832.13 & -2.03 & -22.15 \\
\hline \multicolumn{5}{|l|}{ Memo: } \\
\hline Pago de intereses & -3783.40 & -3619.59 & -7.48 & -7.40 \\
\hline AOD total. excl. deuda & 48299.41 & 45537.79 & 95.50 & 93.14 \\
\hline Alivio neto deuda & 2276.93 & 3354.75 & 4.50 & 6.86 \\
\hline
\end{tabular}

(intereses que, en todo caso, no incluye el CAD en el cómputo de la AOD, a pesar de que suponen una cantidad equivalente a $7.4 \%$ de las ayudas desembolsadas entre 2001 y 2007). Finalmente, el alivio neto de la deuda se ha incrementado en el segundo periodo, suponiendo $6.9 \%$.

\section{CONCLUSIONES}

Los países de ALC han sido importantes receptores de AOD desde que se creara, en la década de los sesenta, el CAD de la OCDE. No obstante, la participación de ALC en el sistema de ayuda ha sufrido una alteración formidable a lo largo del tiempo, de tal modo que las cuotas de participación en la recepción de ayuda mundial se han visto reducidas significativamente, desde valores superiores a $12 \%$ en la década de los sesenta hasta valores inferiores a $8 \%$ en los primeros años del siglo XXI. Esta alteración no se debe tanto al progreso económico logrado por la región -puesto que los países latinoamericanos y caribeños apenas han variado, en términos comparativos, sus posiciones en el abanico de rentas per cápita del mundo en desarrollo- como a los cambios introduci- 
dos en la agenda internacional de desarrollo y, más concretamente, por la definición de una estrategia de objetivos globales de desarrollo que guía las actuaciones de los donantes. Así, los ODM conceden especial atención a los países donde se encuentran las grandes brechas carenciales que entorpecen la consecución universal de los objetivos, lo que está motivando un paulatino proceso de reasignación de la ayuda desde los países con niveles de desarrollo relativamente más elevados, hacia los países más pobres. En este contexto, dado el positivo avance, en términos agregados, de ALC en la estrategia de los ODM -exceptuando los retrocesos experimentados en términos de sostenibilidad medioambiental, y los estancamientos en términos de empleo, alfabetización de los jóvenes y planificación familiar-, el nuevo trazado del mapamundi de la ayuda reduce la importancia de esta región en el sistema, y otorga mayor atención a los países más alejados del cumplimiento de las metas.

Dado el calado que estos acontecimientos tienen en el sistema de cooperación internacional para el desarrollo, en el presente artículo se analizaron los flujos de AOD desembolsados a ALC desde la década de los noventa, indagándose acerca de las implicaciones que la agenda de los ODM ha comportado para la región. Doce resultados relevantes se desprenden de esta investigación:

En relación con las fuentes de financiación externa de ALC:

1. Los flujos de capital externo provenientes de los países de la OCDE han cambiado notablemente en el transcurso de los últimos 17 años: a la par que la financiación externa se incrementaba 5.3 veces a lo largo del periodo, se ha reducido la participación de los flujos públicos de financiación (AOD y otros flujos oficiales) y han cobrando creciente importancia los flujos privados de capital (principalmente, remesas e IED).

En relación con los flujos de AOD:

2. La entrada en vigor de la estrategia de los ODM ha supuesto una reducción moderada de los desembolsos netos de AOD recibidos por los países de ALC, como consecuencia de una paulatina pérdida de relevancia en los presupuestos y estrategias de algunos donantes bilaterales y multilaterales. Consiguientemente, se ha reducido tanto la cuota de participación de ALC en la recepción de AOD global como las ayudas per cápita recibidas.

3. La pérdida de participación de ALC en la recepción de ayuda global ha sido comparativamente mayor que la del resto de PED de ingreso medio.

4. Esta dinámica de reasignación de los recursos se ha visto suavizada por la tendencia alcista experimentada por las cifras de AOD en el arranque del siglo XXI, que ha permitido aumentar las cuotas de ayuda dirigidas a los países más pobres sin necesidad de reducir significativamente los desembolsos dirigidos a los países de desarrollo intermedio. Así, los países de ingreso intermedio han conseguido mantener percep- 
ciones relativamente estables de ayuda per cápita, aun a pesar de haberse reducido las cuotas de participación en la recepción de AOD global. No obstante, el actual escenario de crisis económica mundial amenaza con hacer más "doloroso" el proceso de reasignación. Si la crisis merma el apoyo de los países del CAD, una reducción de los desembolsos de AOD pondrá a los donantes ante un dilema que aún no habían afrontado en lo que va del siglo: avanzar en la reasignación de la ayuda a favor de los países más pobres, tal y como exige la estrategia ODM, pero esta vez a costa de reducir significativamente los "dólares" -y no sólo las cuotas- de ayuda dirigidos a los países de renta media; o mantener inalterado el reparto de la ayuda, al menos hasta que se relaje la restricción presupuestaria -lo que resultaría en un incumplimiento manifiesto de la estrategia ODM-. En semejante escenario de reasignación de la ayuda, los países de ALC tienen mucho que perder.

Respecto a la asignación geográfica de la ayuda entre los países de ALC:

5. La distribución de la ayuda ha sido marcadamente progresiva, beneficiando más proporción a los países con menores niveles de renta per cápita. Además, la capacidad redistributiva de estas ayudas ha mejorado notablemente desde la aprobación de los ODM.

6. No obstante, la distribución de la ayuda per cápita ha tendido a beneficiar a los países estancados en reducir la pobreza (y no tanto a los países que han experimentado importantes retrocesos, como exige la estrategia de los ODM) y a los países poblacionalmente más pequeños.

Respecto a los donantes de la región:

7. Los países de ALC reciben ayuda de los 22 países del CAD, de un buen número de organismos multilaterales de desarrollo, y de varios países donantes que no pertenecen al CAD, si bien los recursos están parcialmente concretados en ocho donantes bilaterales (EUA, España, Alemania, Japón, Canadá, Holanda, Francia y Suecia) y tres organismos multilaterales (Comisión Europea, AIF y BID), que en conjunto aportaron más de cuatro quintos de las ayudas. Entre estos donantes, EUA es el principal financiador de la región, seguido de España (si bien este último es el que más está aumentando sus desembolsos de AOD y el que mayor importancia relativa otorga a la región en sus presupuestos de ayuda) y de la Comisión Europea.

8. Sólo dos donantes del CAD (Canadá y Francia) y un organismo multilateral de carácter no estrictamente regional (el FMI) han incrementado en sus respectivos presupuestos de ayuda la cuota para ALC, mientras que el resto de donantes reducen dichos porcentajes, siendo especialmente severos los recortes practicados por Reino Unido, Italia y Holanda. Además, las estrategias de cooperación de tres países donantes - Reino Unido, Suecia y Alemania- contemplan ya una retirada paulatina 
de la región. En todo caso, ALC continúa siendo la región del mundo en desarrollo con mayor número de organismos multilaterales de carácter regional, y la única que cuenta con un banco de desarrollo multilateral para cada subregión americana.

9. Las ayudas desembolsadas a ALC por los distintos donantes han resultado altamente fragmentadas y volátiles, lo que menoscaba la eficacia de las actuaciones. Sin embargo, dado que en los últimos ańos se está producido una retirada de donantes bilaterales, se está aminorado el problema de la fragmentación, aunque a costa de incrementar la volatilidad de los recursos.

Respecto a la distribución sectorial y las modalidades de AOD:

10. El grueso de los recursos se han dirigido al sector de "infraestructura y servicios sociales" (principalmente al fortalecimiento del gobierno y la sociedad civil, la educación y el control de narcóticos), seguido de las "operaciones de alivio de la deuda" (destacando las practicadas a Nicaragua, Honduras, Bolivia y Guatemala) y las ayudas destinadas a fortalecer los "sectores productivos" y "multisectoriales" (de carácter no medioambiental). Asimismo, la "ayuda programática” está cobrando creciente protagonismo, acorde con el nivel de desarrollo relativamente elevado de la región, y la capacidad de gestión de sus gobiernos -si bien destaca que ALC no sea una de las regiones con mayor porcentaje de ayuda programática.

11. Sin embargo, la distribución sectorial de la ayuda no atiende prioritariamente a los sectores que se han revelado especialmente rezagados de acuerdo con la estrategia de los ODM, especialmente en el caso de la protección medioambiental, las políticas de población y salud reproductiva, y las políticas de empleo.

12. La ayuda no reembolsable ha sufrido un importante incremento, principalmente por la ampliación de las operaciones de alivio de la deuda y de la cooperación técnica, siendo ésta última la que se consagra como principal modalidad de ayuda. A pesar del aumento en las donaciones, el desembolso neto de AOD se ha visto aminorado en el tiempo como consecuencia de la menguada concesión de nuevos créditos y el aumento en las amortizaciones de préstamos pasados (lo que explica también una ligera reducción en el importe de los intereses pagados por ALC).

En suma, los países de ALC receptores de ayuda afrontan un escenario nuevo de participación dentro del sistema de ayuda del siglo XXI. En unos momentos en que la agenda de los ODM prioriza a los países más pobres del planeta y en los que el actual escenario de crisis económica amenaza con contagiar la recesión a las cifras de ayuda, previsiblemente se agravarán los recortes practicados a la región, y, de continuar la tendencia seguida hasta ahora, éstos serán más severos que los que afectarán al resto de PED de similar nivel de desarrollo. La retirada paulatina de ayudas (y, en algunos casos, de donantes) exige renovados esfuerzos para conformar un sistema de AOD más eficiente, que compense la pérdida de volumen con incrementos en la calidad y en el impacto de los 
recursos. Para ello, resulta necesario avanzar en la construcción de nuevos escenarios de coordinación entre donantes, que apuesten por estrategias de delegación, no sólo por la vía multilateral, sino identificando también aquellos donantes que puedan actuar como líderes regionales en la gestión de la ayuda, de acuerdo con una división eficiente de las competencias de cooperación basada en las ventajas relativas de cada actor. Con todo, ALC ofrece un escenario idóneo para poner en práctica la agenda de eficacia de la ayuda que preconizan la Declaración de París, la Agenda de Acción de Accra, el "Código de conducta europeo sobre la división del trabajo y los principios sobre división del trabajo y complementariedad del CAD”, en un contexto de crisis económica internacional que constituye un acicate formidable para avanzar sin dilación por la vía de la innovación y la reforma del sistema de cooperación.

\section{REFERENCIAS}

Comisión Económica para América Latina y El Caribe (CEPAL), CEPALSTAT, 2009, disponible en http://websie.eclac.cl/sisgen/ConsultaIntegrada.asp

Comité de Ayuda al Desarrollo (CAD), Development Database on Aid from DAC Members: DAC online, OECD. Stat, 2009, disponible en http://www.oecd.org/dataoecd/

Sanahuja, J. A., "Seguridad, desarrollo y lucha contra la pobreza tras el 11-S: los Objetivos del Milenio y la 'securitización' de la ayuda”, en Documentación Social, núm. 136, 2005, pp. 25-41.

, "La efectividad de la cooperación al desarrollo entre la Unión Europea y América Latina: balance y perspectivas”, Parlamento Europeo, Dirección General de Políticas Exteriores de la Unión, Nota de Información, 2008.

Sistema Económico Latinoamericano y de El Caribe (Sela), La ayuda oficial para el desarrollo en América Latina y El Caribe, contexto y perspectivas, Caracas, 2005.

Tezanos, S., Cooperación para el desarrollo. Asignación geográfica de la ayuda española, Madrid, Biblioteca Nueva, 2008.

_- "Geopolítica de la ayuda: un mapa estratégico para la cooperación del siglo XxI", en A. Guerra, J. F. Tezanos, y S. Tezanos, La lucha contra el hambre y la pobreza, Madrid, Sistema, 2010.

Tezanos, S. (dir.), América Latina y El Caribe. Mapa estratégico para la cooperación del siglo XXI, Madrid, Civitas, 2010.

Tezanos, S., R. Madrueño y M. Guijarro, "Impacto de la ayuda sobre el crecimiento económico. El caso de América Latina y El Caribe”, en Cuadernos Económicos ICE, núm. 78, 2009, pp. 187-220.

Tezanos, S. y R. Domínguez, "Nueva agenda internacional de desarrollo, ¿̨nuevas perspectivas para América Latina y El Caribe?", en Documentos de trabajo sobre cooperación y desarrollo, núm. 2009/01, Santander, Cátedra de Cooperación Internacional y con Iberoamérica-Universidad de Cantabria, 2009. 
World Bank, World Development Indicators 2009, Washington DC, 2009.

Xalma, C., II Informe de la cooperación sur-sur en Iberoamérica, Madrid, Secretaría General Iberoamericana (Segib), 2009.

\section{ANEXO}

\section{Abreviaturas}

AECID Agencia Española de Cooperación Internacional para el Desarrollo

AIF Asociación Internacional de Fomento

ALC América Latina y El Caribe

AOD Ayuda Oficial al Desarrollo

BID Banco Interamericano de Desarrollo

CAD Comité de Ayuda al Desarrollo

CEPAL Comisión Económica para América Latina y El Caribe

EUA Estados Unidos

FAO Organización de las Naciones Unidas para la Agricultura y la Alimentación

FMI Fondo Monetario Internacional

IED Inversión extranjera directa

ODM Objetivos de Desarrollo del Milenio

OIT Organización Internacional del Trabajo

OMS Organización Mundial de la Salud

ONGD Organización no gubernamental para el desarrollo

ONU Organización de las Naciones Unidas

ONUDI Organización de las Naciones Unidas para el Desarrollo Industrial

PED Países en desarrollo

UNESCO Organización de las Naciones Unidas para la Educación, la Ciencia y la Tecnología

UNTA Cooperación técnica de las agencias de las Naciones Unidas 